\title{
Bound to Happen
}

\section{Explanation Bias in Historical Analysis}

\author{
Aroop Mukharji \\ Ernest May Fellow in History and Policy, Belfer Center for Science and \\ International Affairs, John F. Kennedy School of Government, Harvard \\ University, Cambridge, MA, USA \\ Aroop_Mukharji@hks.harvard.edu
}

\author{
Richard Zeckhauser \\ Frank P. Ramsey Professor of Political Economy, John F. Kennedy School of \\ Government, Harvard University, Cambridge, MA, USA \\ Richard_Zeckhauser@hks.harvard.edu
}

\begin{abstract}
This paper argues that historical analysis, necessarily written with hindsight, often underestimates the uncertainties of the past. We call this tendency explanation bias. This bias leads individuals - including professional historians - to imply greater certainty in causal analyses than the evidence justifies. Their analyses will treat what is plausible to be probable. We offer a few intuitions about why explanation bias exists, its relation to other well-established psychological biases, what it leads to, and how it might be combatted. Appreciating the depth of uncertainty and ignorance in our world is critical for accurately understanding, interpreting, and drawing from the past to illuminate the present and the near future.
\end{abstract}

\section{Keywords}

explanation bias - history - uncertainty - causality - probability - likelihood - analysis

History, the distillation and analysis of the past, offers immense value toward a better understanding of the present and wiser policymaking for the future. History can enrich our awareness of the decision making environment, clarify potential costs and opportunities, and deepen our appreciation of the daunt- 
ing complexity of life. One key aspect of that complexity is that the future is often extremely uncertain, even regarding highly consequential events such as the collapse of the Soviet Union and the eruption of the Arab Spring. Yet, once events have occurred, people armed with the knowledge of hindsight tend to exaggerate those events' predictability and inevitability. To be sure, with the passage of time, documents, research, and perhaps interviews with participants may enable a better understanding of past happenings. Nevertheless, it is inconsistent to view the future as being uncertain but the past as having been predictable. We shall argue in this essay that, to root out that inconsistency, history should be evaluated with much greater attention to the uncertainties of the world.

As residents in a professional school dedicated to policy analysis, we attempt to learn from history how our world might unfold and, in particular, how our actions might affect that unfolding. Our experience suggests that history is not considered deeply enough in the public policy world — neither academically nor in our national discourse. ${ }^{1}$ Yet, investigations into history are prey to numerous intellectual traps, many of which have been examined in the literature. They include the temptation to make superficial analogies, to assume that the past is prologue to the future, to assume that the past was much simpler than the present, and even to assume that the past is more important than it actually is for understanding the present. ${ }^{2}$

This article addresses another trap, important but rarely discussed. We believe that all individuals, including professional historians, ${ }^{3}$ underplay uncer-

1 By this we mean first, that policy schools fail to explain how to appropriately reason from history. Second, although pundits and politicians often employ historical arguments to make their cases, they often do so superficially and selectively.

2 See: Ernest R. May and Richard E. Neustadt, Thinking in Time: The Uses Of History For Decision Makers (New York: Free Press, 1986); Margaret Macmillan, Dangerous Games: The Uses and Abuses of History (Toronto: Viking Canada, 2008); Amos Tversky and Daniel Kahneman, "Judgment under Uncertainty: Heuristics and Biases." Science 185 (4157) (1974), 1124-1131; Yuen Foong Khong, Analogies at War: Korea, Munich, Dien Bien Phu, and the Vietnam Decisions of 1965 (Princeton, NJ: Princeton University Press, 1992); Fredrik Logevall and Kenneth Osgood, "The Ghost of Munich: America's Appeasement Complex." World Affairs 173 (2) (2010), 13-26; and Philip Zelikow, "The Nature of History's Lessons." In The Power of the Past: History and Statecraft, eds. Hal Brands and Jeremy Suri (Washington, D.C.: Brookings Institution Press, 2015), 281-309.

3 We seek to avoid criticizing currently active historians. To provide at least one example up front, we chose to analyze the work of a past historian. In this footnote, we provide an example of explanation bias, though we appreciate we have not yet defined it in the article. We therefore invite readers to return to re-read this footnote after finishing the full text. For an example of explanation bias, consider the following paragraph from Eric Hobsbawm, one of 
tainty to some degree when analyzing historical developments. Specifically, they tend to neglect how uncertain the future appeared to be to those living through past situations. Partly in consequence, people often overvalue their preferred explanations regarding the past, that is, their causal claims for historical events.

Some futures did not happen, but easily might have; that recognition lays bare this overvaluation. As the 9/11 Commission so poetically puts it: "But the path of what happened is so brightly lit that it places everything else more deeply into shadow ... As time passes, more documents become available, and the bare facts of what happened become still clearer. Yet the picture of how

the 21st century's most prominent historians: "But could not the loyalties of the masses be acquired without expensive social policies which might cut into the profits of entrepreneurs on whom the economy depended? As we have seen, it was believed not only that imperialism could pay for social reform but that it was also popular. As it turned out, war, or at least the prospects of successful war, had an even greater built-in demagogic potential. The British Conservative government used the South African War (1899-1902) to sweep away its Liberal opponents in the 'Khaki election' of 1900, and American imperialism mobilized the popularity of guns successfully for the war against Spain in 1898. Indeed the ruling elites of the USA, headed by Theodore Roosevelt (1858-1919, President in 1901-1909), had just discovered the gun-toting cowboy as symbol of true Americanism, freedom and native white tradition against the invading hordes of low-class immigrants and the uncontrollable big city. That symbol has been extensively exploited ever since." With respect to the Spanish-American War in 1898 , Hobsbawm asserts several causal claims without giving evidence or citations. First, he claims that a ruling elite (headed by Roosevelt) mobilized public support for the war. Second, that they used the images of guns and a successful war to do so. And third, that this ruling elite was moved by a spirit of imperialism (he personifies "American imperialism," but contextually he links it with the ruling elite) to declare war. All of these claims are classic cases of explanation bias. First, Roosevelt did not head a ruling elite before the Spanish-American War. In 1898, he had not been governor of New York yet, nor President of the United States. He was the Assistant Secretary of the Navy at the time. Important, but hardly in the driver's seat of foreign policy. The President, William McKinley, would have been shocked to learn that his sub-cabinet official was considered the "head" of a ruling elite. Historians are wont to overstate Roosevelt's role in the 189 os, because (we presume) their knowledge of his presidency and legacy affects their assessment of the past reality. Second, there is little evidence that the image of guns or successful war were purposefully used by the primary decision makers, i.e. President McKinley and his cabinet. To the contrary, many in the cabinet opposed war, and McKinley himself was remarkably private and hesitant in the run-up to the war declaration. This is another case of how knowledge of a future outcome (and prominence, perhaps of the cowboy image) affects the explanation of an event. Lastly, that the United States became an imperial power after the Spanish-American War does not, in itself, imply that imperialism was a driving motivation for the declaration. This is another mistake Hobsbawm makes, again, we believe, driven by explanation bias. His knowledge of future imperialism affects how he understands the motivating forces and attitudes before the war itself. Eric Hobsbawm, The Age of Empire: 1875-1914 (New York: Vintage Books, 1989, 1st ed. 1987), 103-104. 
those things happened becomes harder to reimagine, as that past world, with its preoccupations and uncertainty recedes and the remaining memories of it become colored by what happened and what was written about it later" [emphasis original]. ${ }^{4}$ During any relatively unremarkable stretch of time, there were potential major events that did not happen. We consider, as examples, the lack of any significant, direct, and violent U.s.-Soviet clashes during the Cold War, and the avoidance in the U.s. of a major foreign-launched terrorist event during the years since 2001. Had such events happened, history would have been written far differently, with a greater emphasis on other underlying forces that, perhaps counterintuitively, were also present in the reality of the past.

Social and political movements also challenge confident causal claims. Their progress is highly uncertain. Consider the past decade's unexpectedly rapid acceptance of same-sex marriage, the continued vehemence of the abortion debate, and the worldwide rise of populism. Parsimonious explanations for outcomes that were once highly uncertain should be greeted with skepticism.

This essay addresses the phenomenon of explanation bias, the tendency of historical accounts to trace a clear causal path when contemporary forecasts would have recognized massive uncertainties. ${ }^{5}$ Explanation bias has the unfortunate side effect of inducing individuals to inflate the importance of historical influences and to distort even the nature of history and events themselves. This affects people's interpretations of the past and the lessons drawn from it. There is a witticism among political scientists that anyone with a theory of what causes war should make sure to use wwI as a supporting case. Of course, wwI was so complex that it provided grounds for dozens of competing theories of war. $^{6}$

4 National Commission on Terrorist Attacks upon the United States, The 9/1 Commission Report: Final Report of the National Commission on Terrorist Attacks upon the United States (Washington, D.C.: National Commission on Terrorist Attacks Upon the United States, 2004), 339 .

5 Some contemporary forecasts may have been confident, i.e. assigned extremely high probabilities, but in the opposite direction of what actually happened, for instance, with the Arab Spring or the Soviet Union's collapse, mentioned above. For more on forecasting and expert judgment, see: Jeffrey A. Friedman, War and Chance: Assessing Uncertainty in International Politics (Oxford, uk: Oxford University Press, 2019); Philip E. Tetlock, Expert Political Judgment: How Good Is It? How Can We Know? (Princeton: Princeton University Press, 20o6); Philip E. Tetlock and Dan Gardner, Superforecasting: The Art and Science of Prediction (New York: Crown, 2016); and Don A. Moore, "When Less Confidence Leads to Better Results," New Yorker (25 November 2013), Available: https://www.newyorker.com/business/currency/when -less-confidence-leads-to-better-results. A discouraging theme in these works is that most forecasters, even experts in the field, are overconfident.

6 We are not suggesting here that political scientists differentially suffer from explanation bias. We see it as a general phenomenon, afflicting anyone who makes causal claims about history. 
We do not mean to suggest that explanation bias is a conscious ploy on the part of historians or newscasters to mislead an audience ${ }^{7}$ nor that people encountering historical accounts are dense. Rather, explanation bias is a natural proclivity that affects almost all people some of the time, and some people almost all of the time.

The rest of this article proceeds as follows. We first examine explanation bias, showing that it stems from an underappreciation of uncertainty. After exploring that concept, we distinguish explanation bias from related concepts, such as hindsight bias. We then analyze why and where the bias is most likely to arise, and how it might be combatted. We conclude with brief remarks on the value of embracing uncertainty in historical analysis, and thereby reducing explanation bias.

\section{$1 \quad$ Uncertainty in History}

Life is rife with uncertainty. In decision theory, this term carries a specific meaning. Uncertainty refers to situations in which people know what states of the world might arise, but not their probabilities, as with the questions of who will be the Democratic candidate in 2020 and what will be the mean temperature in New York City in 2030. ${ }^{8}$ Sometimes an outcome happens that was not previously even contemplated, as with the Arab Spring and Soviet Union examples mentioned earlier. We employ the term ignorance to apply to situations in which there are possible states of the world that are not even foreseen as possibilities. $^{9}$

In people's everyday lives, stretching from the parochially personal to the preeminently policy-relevant, uncertainty and ignorance characterize the world. Whether a first date will lead to a lifelong marriage and whether artificial intelligence will throw hundreds of millions out of work-these are

7 Some do intentionally mislead, of course, but that is less our concern. Between the intentionally misleading and the completely transparent and comprehensive, there is an intermediate zone in which it is still argumentatively advantageous to select just the facts, accounts and data that support the thesis.

8 If the probabilities of the known states of the world are known, as with most gambling games, the situation is called risk.

9 See: Richard Zeckhauser, "Investing in the Unknown and Unknowable." Capitalism and Society 1 (2) (2006). As examples, we are ignorant today of what the role of organized religions will be in 2100, and of what the long-term effects of climate change will be. Ignorance is thus an extreme case, beyond uncertainty. It represents an extreme challenge for historical analysis. 
great unknowns. Even specialists would only reluctantly speculate on relations between China and the United States five years from now. The same uncertainty and ignorance characterized historical moments. The 2008 financial meltdown, the vast changes in fertility patterns within a couple of decades, and the $25 \%$ boost in support for same-sex marriage (from 37 to $62 \%$ ) from $2007-$ 2017 were complex changes that were extraordinarily hard to foresee. Such developments were predicted by virtually no one, but comfortably explained by large numbers after the fact. How is that?10

When an explanation is offered for an outcome, the significant uncertainties that prevailed are often ignored or forgotten. To some extent, this is reasonable. Through an outcome, one can know the actual circumstances-what "won out"; furthermore, information comes out after an event that was not known previously. ${ }^{11}$ In the case of the 2008 financial meltdown, this included the degrees of cross claims on and leverage of financial institutions. But actual circumstances are not the same as historical causation, and new information rarely delivers anything close to causal certainty. What caused the meltdown? Was it, as many offer, corporate greed, government deregulation, wildly excessive real estate speculation, a cascading loss of public trust, or panic? And fur-

10 Not all historical events are difficult to explain, of course. Physical events, say a fire, can be diagnosed after the fact. Their source, such as a faulty electrical wire or a dropped cigarette, can often be found. Events that occur multiple times are easier to assess. Often, indeed, analysts do employ probabilities to describe such happenings. Thus, the Federal Reserve has models that diagnose the prospects for a recession within the next year; it reports the results using probabilities. By contrast, it is strange that, when a single large outlier event, such as the 2008 financial meltdown occurs (a unique event that was foreseen by virtually no one), historians and other analysts feel compelled to explain the event's sources, and that, when they do so, they tend to leave little room for uncertainty in their explanations. Although we certainly know more in time, we can be limited by that knowledge too, which depends on what documents were preserved, which participants decided to speak, and whether they spoke honestly. Robert F. Kennedy's Thirteen Days provides a telling example of how historical data, such as memoirs and personal papers, can be inconsistent with facts. The book overstates RF K's role and misrepresents his position during the Cuban Missile Crisis. (He portrayed himself as an important and dovish voice in the room, neither of which he was.) Famed historian Arthur Schlesinger, Jr., supported the distorted reality in his 1978 biography of RFK, since RFK's personal papers seemed to evidence it. Yet the true nature of the ExComm conversations only was revealed years later when JFK's secret tapes were released to the public. Robert F. Kennedy, Thirteen Days: A Memoir of the Cuban Missile Crisis (New York: W.W. Norton, 1969); Arthur Schlesinger, Jr, Robert Kennedy and His Times (Boston, MA: Houghton Mifflin, 1978); Ernest R. May and Philip Zelikow, The Kennedy Tapes: Inside the White House During the Cuban Missile Crisis (Cambridge: The Belknap Press of Harvard University Press, 1997); Sheldon M. Stern, "The Cuban Missile Crisis ExComm Meetings: Getting it Right After 50 Years." History News Network (15 October 2012), Available: https://historynewsnetwork.org/article/1488o2. 
ther, why do these seemingly common phenomena not produce global financial crises much more often? Most retrospective explanations blame a confluence of these forces for producing the meltdown, but they do not make it clear how many different alternative futures were plausible to critical decision makers as well as to ordinary folks at the time.12 That is how we forget about uncertainty (and ignorance) and instead prioritize an explanation that might feel reasonable. Though a reasonable explanation can illuminate a logical pathway to the outcome observed, it neither can nor should existentially rule out alternative explanations. ${ }^{13}$

Good historians, of course, do not write with a sense of historical determinism. They acknowledge that other futures might well have transpired and that the record of what actually happened may not be crystal clear. Still, causal claims are treated less formally in history than they are in political science and economics. ${ }^{14}$ Elegant historical narratives serve as a form of camouflage. When explanations are offered, they are rarely rigorously pitted against competing explanations. This makes it difficult to know what else might have happened, given the initial conditions that we understood. Exploring alternative explanations can be tedious and almost certainly will interrupt the flow of a narrative, which is itself a persuasive device. But what is plausible is not necessarily what is probable. And that is doubly true when plausibility is distilled in retrospect.

Only a historian who directly engages with a range of rival arguments (or, relatedly, entertains counterfactual analysis) can arrive at a compelling conclusion as to what might have caused what actually occurred. ${ }^{15}$ It would

12 David Carr makes the related point that, in hindsight, individuals situate an action in relation to events that actually followed, but agents in history may have projected or intended different future realities that simply did not pan out. David Carr, "Place and Time: On the Interplay of Historical Points of View." History and Theory 40 (4) (2001), 159.

13 Think of an analogy to elderly Uncle George, gravely ill in the hospital. Doctors say he might not survive for another two nights, but he pulls through and lives a number of additional years. Elderly Uncle Ralph is in equivalent danger with the same disease, but he perishes. An autopsy reveals that his condition simply overwhelmed his heart. A proper retrospective analysis would say that, for an elderly man, this disease may be fatal. It might use an organ-by-organ assessment to refine its prediction, but it would still assign only probabilities, not causal certainties. Autopsies (now speaking metaphorically) can of course be helpful, but mono-causal phenomena are exceedingly rare. One that does come to mind, that was also revealed in a post-mortem, was the O-Ring failure discovered by Richard Feynman that led to the Challenger disaster in 1986.

14 Though, as our wwi example earlier in the article indicates, political scientists also overstate causal claims, as do economists, despite their self-righteous assertions about causal punctiliousness. Our point is that explanation bias afflicts all people when telling historical accounts.

15 See: Fredrik Logevall, "Presidential Address: Structure, Contingency, and the War in Viet- 
be painstaking, even counterproductive, to do so for every causal claim that is made; after all, they are everywhere. ${ }^{16}$ However, the best analyses must acknowledge the underlying uncertainty and ignorance that existed at the moment. This can be accomplished by clarifying what decision makers and the public knew and did not know, noting how they conceived of different futures, and incorporating the unique effects that uncertainty had on decision making. ${ }^{17}$ Undertaking this for every central causal claim would be challenging; but for major questions of history, it would seem necessary if one is accurately to portray and explain the past.

Explanation bias refers to the tendency of individuals to assess greater certainty about historical causality than the evidence justifies. That bias is intimately linked to the concepts of uncertainty and ignorance, in that it refers to their

nam." Diplomatic History 39 (1) (2015), 1-15; Philip E. Tetlock and Geoffrey Parker, "Chapter 1: Counterfactual Thought Experiments." In Unmaking the West: "What-if?" Scenarios that Rewrite World History, eds. Philip E. Tetlock, Richard Ned Lebow, and Geoffrey Parker (Ann Arbor, MI: University of Michigan, 2006), 14-46; Martin Bunzl, "Counterfactual History: A User's Guide." The American Historical Review 109 (3) (2004), 845-858; and Niall Ferguson, ed., Virtual history: Alternatives and Counterfactuals (New York, NY: Basic Books, 1997).

16 For an illustrative example of explanation bias in academic history, please see footnote 3 . For an instructive example in popular history of how frequent unsupported causal claims can be, consider just half of a paragraph from Henry Kissinger's Diplomacy on Wilson's decision to enter WWI. In three sentences, he makes three separate causal claims (each numbered in our brackets). "What extraordinary conceit to derive a charter for global intervention from a Founding Father's injunction against foreign entanglements, and to elaborate a philosophy of neutrality [1] that made involvement in war inevitable! [2] As Wilson edged his country ever closer to the world war by articulating his visions of a better world, he evoked a vitality and an idealism that seemed to justify America's hibernation for a century just so it could now enter the international arena with a dynamism and an innocence unknown to its more seasoned partners. [3] European diplomacy had been hardened, and humbled, in the crucible of history; its statesmen saw events through the prism of many dreams proved fragile, of high hopes dashed and ideals lost to the fragility of human foresight." Henry Kissinger, Diplomacy (New York: Simon and Schuster, 1994), 48.

17 The literature on judgment under uncertainty is rich. Two classic articles that remain highly relevant today are: Tversky and Kahneman (1974); and Daniel Kahneman and Amos Tversky, "Prospect Theory: An Analysis of Decision Under Risk." Econometrica 47 (2) (1979), 263-291. For recent and thorough overviews of behavioral economics, see: B. Douglas Bernheim, Stefano Dellavigna, and David Laibson, Handbook of Behavioral EconomicsFoundations and Applications, Vol. 1 and Vol. 2 (Amsterdam, 2018, 2019). 
undervaluing in historical analysis and to the overvaluing of a specific causal explanation for a given event.

Explanation bias is related to a few familiar concepts in decision making and logic: the availability heuristic, hindsight bias, and the post hoc fallacy. These concepts are worth visiting to better understand what explanation bias is and how it differs from well understood phenomena.

\subsection{Availability Heuristic}

The foundational work of behavioral psychologists Amos Tversky and Daniel Kahneman shows that individuals tend to give excess weight to the explanatory value of more easily imaginable or more easily recalled instances and experiences. ${ }^{18}$ For instance, if individuals have friends who have suffered some medical ailment, they might think their chances of suffering the same fate are far greater than proper Bayesian updating would imply. This is the availability heuristic: what more easily comes to mind overly inflates an individual's calculations of likelihood.

Explanation bias is in some ways the fruit of the availability heuristic. Specifically, the availability heuristic may help to explain why the explanation bias exists: the more easily a plausible explanation of a historical happening springs to a person's mind, the greater the probability that individual will tend to believe that it actually caused the outcome. That may be particularly the case for the poorly informed, who are then less likely to consider competing explanations for historical events.

\subsection{Hindsight Bias}

Hindsight bias refers to the tendency by individuals to exaggerate, in hindsight, what they could have predicted in foresight. ${ }^{19}$ In other words, after a past event, individuals tend to believe they were more certain about the outcome that happened than they actually were, a phenomenon that Baruch Fischhoff labelled "creeping determinism." The election of Donald Trump in 2016 offers an example. While most Democrats readily admit they were strongly surprised by his victory, many more today (than at the time) claim to have had real concerns in

18 Tversky and Kahneman (1974).

19 See: Baruch Fischhoff, "Hindsight not Equal to Foresight: the Effect of Outcome Knowledge on Judgment Under Uncertainty." Journal of Experimental Psychology: Human Perception and Performance 1 (1975), 288-299; and Baruch Fischhoff, "For Those Condemned to Study the Past: Heuristics and Biases in Hindsight." In Judgment Under Uncertainty: Heuristics and Biases, eds. Daniel Kahneman, Paul Slovic, and Amos Tversky (Cambridge, UK: Cambridge University Press, 1982), 335-351. 
the run-up to election day. But hindsight bias tells us that these individuals now exaggerate the concerns they held then. That is because, in hindsight, people have a hard time recalling how much they did not know at the time (i.e. their past uncertainty), and their knowledge of the outcome influences their memories.

While hindsight bias refers to an inflated confidence that one had foreseen a past outcome ex ante, explanation bias refers to an inflated confidence in a particular explanation for a past outcome ex post. Two quite different parties are susceptible to explanation bias in a historical account: the originator, namely the historian or analyst, and the consumer, the individual reading the account. Consumers are generally at a disadvantage in drawing conclusions from such accounts, since they are often much less knowledgeable than the historians, who will have selected evidence that supports their chosen causal explanations.

\subsection{Post Hoc Fallacy}

The post hoc fallacy is a logical fallacy in argumentation that also contributes to explanation bias. It is shorthand for post hoc, ergo propter hoc, or, literally, "after this, therefore because of this." It refers to the mistaken assumption that Event A caused Event B because Event A happened before Event B. ${ }^{20}$ Suppose that an athletic team experiences a turbulent flight to its next match and then loses. Assuming that the team lost because of the flight would represent the post hoc fallacy. It could be that the team lost because of the flight, or because the other team took steroids, or because the turf favored the opponents, or because of a host of other reasons. Even the coach may not know which event contributed what amount to the team's loss.

Related to explanation bias, the post hoc fallacy describes a potential source of mistaken assumptions for a given causal explanation. Explanation bias refers to that specific explanation's being overvalued, but does not offer a reason for the explanation that was chosen. That choice could be due to any number of reasons, including the post hoc fallacy. The sequential nature of events implied by the post hoc fallacy adds to the plausibility of an explanation. And the more plausible an explanation appears, the more likely it is to be believed and overvalued.

20 The related cum hoc fallacy, or, cum hoc, ergo propter hoc, refers to the mistaken assumption that Event A causes Event B because Event A happens at the same time as Event B. It literally translates to "and this, therefore because of this," and is also captured across statistics classes worldwide in the warning "correlation does not imply causation." 


\subsection{Explanation Bias: Why It Might Happen, When It Might Happen, and How It Can Be Combatted}

Explanation bias is different from the terms above. It refers to the tendency to inflate the likelihood that a proposed causal pathway applies when explaining a historical event. For example, after Donald Trump's surprise election in 2016, a number of explanations were offered: disgruntled victims of globalization and market capitalism, a growing urban-rural rift, a resurrected white nationalism, and a newly impassioned voting bloc of poor white voters. Clearly, Donald Trump won the election, and we know pretty well who voted for him, in what numbers, and in what places around the country. But he easily may not have won, and these explanations are influenced by the knowledge that he did. ${ }^{21}$

In the spirit of Sherlock Holmes and the famed case in which the dog did not bark, ${ }^{22}$ these explanatory factors hardly received much attention in the prognostications prior to the election. That at least suggests that other factors strongly contributed to Trump's victory. It is not easy to determine this. It is so hard, in fact, that during the election campaign itself, half the country appears to have been blind to the precipitating movements that appear so vivid today to pundits in hindsight. Yet when the history of Barack Obama's second term and even of the 199os onward is told, it will likely forever be changed by the revelation that Donald Trump triumphed in Obama's wake. People will be led to believe that any of these growing forces was a clear and recognized pathway to Donald Trump's presidency, despite the reality that few saw them both coming and powerful, and that the election hinged on some several thousand votes in critical states. ${ }^{23}$

To be clear, our argument is far from being a statement that: "Nothing can be explained." Rather, we are observing that uncertainty and ignorance almost always receive too little attention when history is told (by anyone), leading to overconfidence in causal explanations of past events.

21 If Trump wins in 2020, will it be because of his romance with white supremacy, a strong economy, the anticipated fiscal irresponsibility of the Democrats, or something else entirely? It is noteworthy that after the election, experts will claim to have the answers, but today no one would claim to know what holds the most explanatory value. Is it likely that the passage of time will somehow reveal that? (See the first paragraph of our article, "To be sure ...").

22 Arthur Conan Doyle, "The Adventure of Silver Blaze." In The Memoirs of Sherlock Holmes (New York: Harper and Brothers, 1894), 1-28.

23 Of course, professional historians have yet to produce analyses of Trump's path to victory, and indeed some may emphasize the contingency, complexity, and surprise of his win. We will not know for some time. Our suspicion is that even still, in those future histories, certain social forces will be highlighted that would not have been highlighted in the telling of a Clinton win. 
The way we should tell the story of Trump's 2016 victory would be to grapple with those uncertain circumstances. Analysts would acknowledge the range of proffered explanations, test each against the competing evidence, and then assign weights to the likely importance of competing (and supporting) explanations. That process should be accompanied by a stress on the underlying uncertainty of the pre-election environment. On Election Eve, Trump was a substantial underdog, but he won. Had it been clear why he would win, perhaps because of his support from white working-class males or because Hillary Clinton had insufficiently visited critical states, he would have been an odds-on favorite.

A brief analysis of the reporting of major newspapers illustrates explanation bias in action. We examine how often certain demographic phrases, such as "working-class men" (presumed to be a critical source of advantage for Trump), were used to explain the result in the 3o-day period after the 2016 U.s. presidential election. ${ }^{24}$ Examining three major national daily newspapers, ${ }^{25}$ we compared their usage to phrases such as "suburban women" (a presumed Clinton advantage). Those explaining Trump's advantage were invoked in about twice as many articles. We compared these ratios of usage to those for 30 days before the election. Those ratios hovered around 2/3. In short, phrases favoring Trump (Clinton) were used much more (less) often after the election than before. See results below in Table $1 .{ }^{26}$

This implies the election changed how often reporters identified the same demographic forces once the surprising result was known. ${ }^{27}$ What's more is that when we analyzed the invocation of certain explanatory phrases, like "populism," "globalization" and "white nationalism," the differences were even larger. Between 2.5 and 3 times as many articles invoked these phrases in the after versus before period, from when Trump won to when Clinton was heavily favored.

Explanation bias is a general phenomenon. Why do even many historiansprofessional explainers of history—not manage to avoid it? So as not to sail into our own trap and explain too confidently, we will merely suggest some possibly contributing factors.

\footnotetext{
24 The phrases were identified before examining usage.

25 The New York Times, Washington Post, and Wall Street Journal.

26 For a full description of our analysis, please see Appendix.

27 In fairness, we should expect turnout and exit polls to refine voting estimates. But we should not expect them to swing so drastically when explaining a razor-thin victory.
} 
TABLE 1 Explanatory phrases usage after and before 2016 election outcome

\section{Trump-favoring After Before Ratio Clinton-favoring After Before Ratio}

\begin{tabular}{lcccllll}
\hline Poor Whites & 318 & 206 & 1.54 & $\begin{array}{l}\text { Suburban } \\
\text { women/woman }\end{array}$ & 50 & 87 & .575 \\
$\begin{array}{l}\text { Working-class } \\
\text { men/man }\end{array}$ & 182 & 97 & 1.88 & $\begin{array}{l}\text { College-educated } \\
\text { women/woman }\end{array}$ & 29 & 45 & .644 \\
$\begin{array}{l}\text { Blue-collar } \\
\text { men/man }\end{array}$ & 66 & 30 & 2.20 & $\begin{array}{l}\text { College-educated } \\
\text { men/man }\end{array}$ & 20 & 30 & .667 \\
\hline
\end{tabular}

Note: Usage in the New York Times, Washington Post, and Wall Street Journal. "After" dates: 9 OCT 2016 to 7 NOV 2016. "Before" dates: 9 NOV 2016 to 8 DEC 2016. Listed in order of total number of articles citing term.

First, many historians write works that are permeated with deeply-held theoretical assumptions about how the world works. ${ }^{28} \mathrm{~A}$ person who believes that market capitalism is a primary determinant of human behavior, will probably be more likely to think market capitalism was a primary determinant of any particular historical event. The same might go for rational actor theory, racial theories, gender theories, or any number of other theories of behavior that appeal to particular historians. But it is implausible that a single theory of human interaction could explain the multiple events that a single historian might address in a career. ${ }^{29}$ Some events should be explained by some reasons

28 For any major question of history, an individual is confronted with mountains of data that would be impossible to read in a lifetime. They must look at archival data selectively; there is no other way to do it and still eat, breathe, and sleep. That selectivity is based on what they think is important. What they think is important is based on a hunch. And hunches are influenced by intuitions about how the world works.

29 The so-called Wisconsin School of diplomatic history, which prioritizes economic explanations of American foreign policy and has produced some of the biggest names in the field of American foreign relations, is a case example of a theory of history centered on a single explanatory variable. A telling example of a founding member of the Wisconsin School falling prey to explanation bias is historian William Appleman Williams. On the topic of the annexation of the Philippines after the Spanish-American War, he writes: "Subsequent analysis and actions established McKinley and his close associates as vigorous participants in the debate itself [to acquire the Philippines], and further suggest that those men did much to work out the strategy of empire that was ultimately accepted by the country at large." Here explanation bias stems from Williams' knowledge that President McKinley eventually favored acquisition of the island chain, mistakenly assuming that he had had a deliberate strategy to do so for months, if not years. To the contrary, the evidence 
in a hierarchy of causation, and others by a different set in a different hierarchy. We would thus expect explanation bias to more acutely afflict more ideologically driven individuals. ${ }^{30}$

A second source of explanation bias, informal and academic incentives for explicating history, could also help to promote this bias. The rewards are modest for acknowledging uncertainty in one's analysis. We will employ three fictitious accounts to illustrate. A historian would receive no extra points (and would perhaps be penalized) for this analysis: "Disgruntled working class males probably helped Trump win in Michigan, but probably less so in Wisconsin, and it is too hard to say whether they played more of a role than general softness in the economy in either state." By contrast, the following narrative might well bring plaudits: "Since the 199os, the widespread embrace of globalization neglected the hundreds of thousands - if not millions - of Americans who lost their jobs and fell through the cracks. While the rest of the country was prospering, they were left behind. Donald Trump was the first major political candidate to acknowledge this gap and challenge orthodoxy around the issue. That enabled him to get elected; it was his appeal to disgruntled victims of globalization." The latter argument is clearer, more elegantly stated, but leads the reader to conclude that the claims is overwhelmingly conclusive.

Stories and narratives are intended to be persuasive devices. If the second account were accompanied by a few corroborating interviews, which would be easy to find (even if the associated views are held by relatively few), that would make for a clear causal story that many would find convincing. But what of the following more cautious account: "In predominantly white working-class

suggests that McKinley was undecided on acquiring the islands throughout most of 1898 . The fate of the Philippines was actually quite uncertain, even in McKinley's own mind, until October 1898, when he finally instructed his Paris Peace Commissioners to negotiate the acquisition. William Appleman Williams, The Tragedy of American Diplomacy, Fiftieth Anniversary Edition (New York: W.W. Norton, 2009, 1st ed. 1959), 48. For a detailed and thorough account of McKinley's decision making with respect to the Philippines, see: Philip Zelikow, "Why Did America Cross the Pacific? Reconstructing the U.s. Decision to Take the Philippines, 1898-99." Texas National Security Review 1 (1) (2017), 36-67.

30 Some research in political science suggests that experts with strong ideological commitments are more likely to reject close-call counterfactuals, thereby indirectly exhibiting explanation bias. This research, however, also cautions that openness to historical contingency also has a downside; it may lead to too much subjective probabilities assigned to too many scenarios. Philip E. Tetlock and Richard Ned Lebow, "Poking Counterfactual Holes in Covering Laws: Cognitive Styles and Historical Reasoning." American Political Science Review 95 (4) (2001), 829-843; and Philip E. Tetlock, "Theory-Driven Reasoning about Plausible Pasts and Probable Futures in World Politics: Are We Prisoners of Our Preconceptions?" American Journal of Political Science 43 (2) (1999), 335-366. 
counties in these three states, Trump secured $45 \%$ of the vote, compared with $36 \%$ for Romney in 2012. Statistical analysis shows that these swings would have been $70 \%$ likely to tip the outcomes in all three of these states, assuming that other counties had behaved as they did in presidential elections stretching back to Eisenhower." This purely analytic treatment, which replaces the linear political story with a probabilistic assessment, might be more accurate, but also less appetizing to publishing houses and journals (except, perhaps, this one). ${ }^{31}$

A third source of explanation bias could relate to discomfort from the cognitive dissonance encountered when giving fair hearing to competing theories. Humans generally have a hard time juggling competing hypotheses. ${ }^{32} \mathrm{~A}$ single explanation, especially one explained narratively, can be preferable precisely because individuals have an easier time understanding and being persuaded by it. While this could help account for explanation bias among producers of history (of any kind), it may better explain the strength of explanation bias's adoption among its consumers. Consumers of history who have less knowledge than its purveyors may also be less aware of competing theories and, therefore, even more susceptible to explanation bias.

We see no clear and simple ways to eliminate explanation bias. We do feel, however, that there may be certain methods for reducing it; in naming the bias, we also hope that drawing attention to it is a first step forward. These countering methods are also speculative, but they relate to the underlying intuition about the bias itself. First, for instance, we suspect the acquisition of knowledge (reading, researching, etc.) would tend to attenuate explanation bias for consumers of history. If less awareness about a topic (hence less awareness of conflicting evidence) can lead to greater explanation bias, then greater knowledge should tend to lessen this bias. Such lessening can be accomplished by reading varying explanations of a historical event, including those written by historians from different eras. History, much like other areas of inquiry, has popular ideological and methodological trends that change with each generation. ${ }^{33}$

31 Some presses are further to blame for their disappointing practice of publishing a separate endnotes section at the end of a book rather than footnotes (or chapter endnotes) throughout. While the information is all the same in the book, the rather cosmetic marginal benefit of tidying up the body of the text is vastly outweighed by the marginal cost of encumbering transparency. Nobody enjoys flipping to page 843 to read a citation, so fewer citations will be read.

32 The cognitive dissonance literature dates at least to 1957 with Leon Festinger, $A$ Theory of Cognitive Dissonance (Palo Alto, CA: Stanford University Press), 1957.

33 Though, instead of calling these phenomena "trends" or "fads," historians tend to call them "turns." 
Second, for historians, the same skilled processes used to find confirming evidence should be used to challenge a theory. In short, one should try to debias the search for evidence. ${ }^{34}$ We believe that a contrarian cast of mind is a beneficial attribute for historical explanation, much as it is for many academic disciplines. Good scholars in any field of theory and analysis should attempt to be contrarians, even (maybe especially) with respect to their own work.

Third, we feel that familiarity with decision science can help clarify causal inference, identify common decision making pitfalls, and expose individuals to competitive explanations in other contexts. These, of course, are meant to complement, not to supplant, rich historical methods. Coming from an interdisciplinary institution, we have observed that members of different academic fields can offer great insights to each other. Decision science is a field dedicated to how humans grapple with competing values and uncertainty, and how they can do so in ways that make them better off. Incorporating decision science into the study of history is not easy (though a few political scientists and historians have done $\mathrm{so}^{35}$ ), but even a basic knowledge of its intuition and methods can be immensely instructive. Decision science can help clarify how one thinks about causes and effects, competing evidence, and subjective probabilitiesall intuitively useful analytical tools for examining historical events.

Lastly, we feel that historical simulations - group case studies of historical decisions - are an excellent way to put individuals back into conditions of the past and to witness and wrestle with (as best as possible) the complexities and uncertainties around policymaking. Professors at our home institution have designed a number of these cases, and they are increasingly adopted in classrooms elsewhere in the nation. ${ }^{36}$ One of the most instructive sample cases was

34 In fairness, especially given footnote 28 about at the amount of data a historian must sift through just to prove a single explanation, it is worth admitting that we do not find these solutions to be practically simple or easy. Proving a plausible explanation is difficult enough. We do feel, though, that acknowledgement of uncertainty, recognition of alternatives, and some degree of engagement with those alternatives are possible, though difficult. Analytical rigor would be enhanced. For an academic treatment of corrective procedures, see: “Part ViII: Corrective Procedures." In eds. Kahneman, Slovic, and Tversky (1982), 391-462.

35 For instance, Robert Jervis, How Statesmen Think: The Psychology of International Politics (Princeton, NJ: Princeton University Press, 2017); Robert Jervis, Perception and Misperception in International Politics, (Princeton, NJ: Princeton University Press, 1976); Rose McDermott, Risk-Taking in International Relations: Prospect Theory in Post-War American Foreign Policy (Ann Arbor, MI: University of Michigan Press, 1998); Deborah Welch Larson, Origins of Containment: A Psychological Explanation (Princeton, NJ: Princeton University Press, 1985); and Khong (1992).

36 A number of older (but still illuminating) cases are detailed in May and Neustadt (1986), 
written in the 198 os by scholars at the Harvard Kennedy School; it addresses the secession crisis in the United States. ${ }^{37}$ Students play the role of British merchant bankers, holding railroad options that would expire on April 12, 1861, the day Confederates attacked Fort Sumter. Students are given a range of materials, newspaper articles, and other analyses, and are asked whether they would have exercised the option and bought the shares, which would be worth less in the event of hostilities. Through this exercise and despite the fact that they know the historical outcome, individuals develop an appreciation for how hard it was in the historical moment to predict one of the most consequential events of American history. ${ }^{38}$ This, in turn, we feel, should affect how those students approach that historical event and explain it.

A further and related advantage of the case study method is that it emphasizes the elasticity of the historical present. In cases where students are put in the seats of decision makers themselves, they may more easily appreciate that historical events are rarely (if ever) predetermined and may depend on a series of individual choices, each of which could lead the world in a different direction. The case study method is not unique in teaching this lesson; counterfactual analysis of certain decision nodes or simply reading history incorporating that uncertainty and malleability would also accomplish this. ${ }^{39}$

\section{$3 \quad$ Concluding Remarks}

We believe that explanation bias is a common phenomenon that affects all people. It refers to the neglect of uncertainty in historical explanation and the consequent overvaluing of one's logical pathway. In short, it means that, for

283-294 (Appendix C). For more recent group case studies, see also: David Moss, Democracy: A Case Study (Cambridge, MA: Harvard University Press, 2017); and Philip Zelikow and Ernest R. May, Suez Deconstructed: An Interactive Study in Crisis, War, and Peacemaking (Washington, D.C.: Brookings Institution, 2018).

37 Ellsworth D. Draper, Joshua L. Rosenbloom, Melanie Billings-Yun, and Richard E. Neustadt, "Secession: C14-82-435, C14-82-435S, C14-82-436, and C14-82-427." Harvard Kennedy School Case (Cambridge, MA: Harvard Kennedy School, 1983). The case scenario for students is described in May and Neustadt (1986), 259-261.

38 Reducing the decision to a monetary one isolates the question of uncertainty, which may be more easily understood in financial terms. Acting as a British national minimizes the pre-conceived notions with which a Southerner or Northerner might have approached the situation.

39 It is worth adding that uncertainties about the future do not only stem from the choices of decision makers. Other elements, like the tides of mass opinion, may also figure into the mix. 
many people and situations, a plausible explanation of the past becomes the probable, even definitive, explanation of the past.

Appreciating the depth of uncertainty and ignorance in our world is critical for accurately understanding, interpreting, and drawing from the past to illuminate the present and the near future. From recent scholarly work in political science and decision making, we know that experts tend to underperform in probability assessments relative to individuals who openly acknowledge their uncertainty about the world. ${ }^{40}$ Thus, a readiness to admit and internalize this uncertainty is not an intellectual vulnerability. It is precisely the opposite: an analytical strength. In the words (perhaps) of Winston Churchill: "True genius resides in the capacity for evaluation of uncertain, hazardous, and conflicting information." ${ }^{\text {11 }}$ Uncertainty delivers us a past that that is relatable and instructive. It powerfully teaches us about how decision makers really make policy and warns us of the effects an uncertain world can have on the process. But we stifle (or worse, distort) those lessons when we place excessive confidence in our explanations of historical events.

Questing individuals need not succumb to the trap of overconfident historical analysis. Embracing uncertainty offers each of us a way to counteract explanation bias and to put ourselves in the shoes of the decision makers and ordinary folks as they stood facing the immense complexity of their eras. Appreciating that uncertainty is one of history's greatest lessons.

\section{Acknowledgments}

The authors thank Bradley DeWees, Paul Behringer, Fredrik Logevall, Philip Tetlock, Lawrence Summers, and Philip Zelikow for their helpful comments in the drafting process. They also thank the anonymous reviewers.

40 See: Tetlock and Gardner (2016).

41 Our "perhaps" follows our theme to recognize historical uncertainty for a quote often attributed to Churchill, with proper attribution unavailable. 


\section{Appendix: Newspaper Analysis}

Overview of procedure: Using the ProQuest Historical Newspapers database, ${ }^{42}$ we searched three newspapers (the New York Times, Washington Post, Wall Street Journal) for the number of articles that invoked election-relevant terms. For each term, we compared the results for the period 30 days after the election (9 November 2016 to 8 December 2016) to the results for the period 30 days before the election (9 October 2016 to 7 November 2016). This allowed us to calculate the comparative ratios of frequency referenced in Table 1.

Methodological decisions: We subset the searches to the following newspaper listings: The Washington Post (1974-Current file), New York Times (2008-Recent), Wall Street Journal (1923-Current file), New York Times (1923-Current file), Wall Street Journal, Wall Street Journal (Online), The Washington Post (2008-Recent). For our dates of interest only the following listings returned results: New York Times (2008-Recent), Wall Street Journal, Wall Street Journal (Online), The Washington Post (2008-Recent). These listings include print articles from the New York Times and Washington Post, and both online and print articles from the Wall Street Journal. Given that Wall Street Journal (Online) returned print articles (that were not included in the other Wall Street Journal listing) as well as online articles, there was no clear way for us to restrict all searches to print articles across all three newspapers.

Our search terms are not set in quotation marks (e.g. we searched [suburban women] not ["suburban women"], the latter approach which preserves the twoword phrase). We forwent quotation marks because doing so would have drastically reduced the number of results. For instance, "suburban women" does not appear as a two-word phrase very often (it also appears as "suburban dwelling women" and "suburban white women" etc.), so one can get a more accurate read on the number of articles referencing suburban women by leaving out the quotation marks. The downside here is that the results also pick up articles that contain both words from the search term (i.e. both "women" and "suburban"), but the two terms may not necessarily be referenced near each other in the text, thereby reducing the chance the article has anything to do with the 2016 election. In order to crudely remove those cases, we added the following search terms to the string: "Trump," "election," and "Clinton." This returned results that were more likely to reference, e.g. [suburban women], in the context of the 2016

42 ProQuest Historical Newspapers, Online, Available: https://www.proquest.com/products -services/pq-hist-news.html. 
presidential election. Expectedly, this reduced the overall number of articles returned in the results (relative to the exclusion of those three election terms), but the ratios remained consistent, and even strengthened in some cases.

Another challenge was that some articles reference search terms in a nonexplanatory way (e.g. describing voting patterns). The only way to remove those cases is to read each individual article and make a determination as to whether it was explanatory or non-explanatory. Given that our data number over 2000 articles, we have not undertaken this.

We first consider terms favoring Trump, and then those favoring Clinton. In each case, we present the terms with the greatest usage first. These terms were identified before securing the newspaper database..$^{43}$ Finally, this appendix, but not the paper, considers four non-demographic terms that were used to help explain the Trump victory.

A1 Terms Favoring Trump

A1.1 Search Term: (poor whites)

ProQuest search string: pub.Exact("The Washington Post (1974-Current file)" OR "New York Times (2008-Recent)" OR "Wall Street Journal (1923-Current file)" OR "New York Times (1923-Current file)" OR "Wall Street Journal" OR "Wall Street Journal (Online)" OR "The Washington Post (2008-Recent)") AND (poor whites) AND ((Trump) OR (election) OR (Clinton))

Number of articles in the 30 days post: 318 Number of articles in the 30 days prior: 206 Ratio:

A1.2 Search Term: (working-class men) OR (working-class man)

ProQuest search string: pub.Exact("The Washington Post (1974-Current file)" OR "New York Times (2008-Recent)" OR "Wall Street Journal (1923-Current file)" OR "New York Times (1923-Current file)" OR "Wall Street Journal" OR "Wall Street Journal (Online)" OR "The Washington Post (2008-Recent)") AND ((working-class men) OR (working-class man)) AND ((Trump) OR (election) OR (Clinton))

43 We identified and searched for two other terms, but we did not include their full results in the appendix since each of those searches returned under 5 o total cites. Even with those terms, however, our results were consistent with our hypothesis and other results. Those terms include: (1) non-college-educated (Post: 9, Prior: 12, Ratio: 1.33); and (2) urban rural divide on urban rural rift $(6,12,2)$. 
Number of articles in the 30 days post: 182

Number of articles in the 30 days prior: $\quad 97$

Ratio:

A1.3 Search Term: (blue-collar men) or (blue-collar man)

ProQuest search string: pub.Exact("The Washington Post (1974-Current file)" OR "New York Times (2008-Recent)" OR "Wall Street Journal (1923-Current file)" OR "New York Times (1923-Current file)" OR "Wall Street Journal" OR "Wall Street Journal (Online)" OR "The Washington Post (2008-Recent)") AND ((bluecollar man) OR (blue-collar men)) AND ((Trump) OR (election) OR (Clinton))

Number of articles in the 30 days post: 66

Number of articles in the 30 days prior: 30

Ratio:

\section{A2 Terms Favoring Clinton}

A2.1 Search Term: (suburban women) OR (suburban woman)

ProQuest search string: pub.Exact("The Washington Post (1974-Current file)" OR "New York Times (2008-Recent)" OR "Wall Street Journal (1923-Current file)" OR "New York Times (1923-Current file)" OR "Wall Street Journal" OR "Wall Street Journal (Online)" OR "The Washington Post (2008-Recent)") AND ((suburban women) OR (suburban woman)) AND ((Trump) OR (election) OR (Clinton))

Number of articles in the 30 days post: $\quad 5^{\circ}$

Number of articles in the 30 days prior: 87

Ratio:

A2.2 Search Term: (college-educated women) or (college-educated woman) NOT (non-college-educated)

ProQuest search string: (pub.Exact(“The Washington Post (1974-Current file)" OR "New York Times (2008-Recent)" OR "Wall Street Journal (1923-Current file)" OR "New York Times (1923-Current file)" OR "Wall Street Journal" OR "Wall Street Journal (Online)" OR "The Washington Post (2008-Recent)") AND ((college-educated women) OR (college-educated woman)) AND ((Trump) OR (election) OR (Clinton))) NOT non-college-educated

Number of articles in the 30 days post: 29

Number of articles in the 30 days prior: 45

Ratio: 
A2.3 Search Term: (college-educated men) or (college-educated man) Not (non-college-educated)

ProQuest search string: (pub.Exact("The Washington Post (1974-Current file)" OR "New York Times (2008-Recent)" or "Wall Street Journal (1923-Current file)" on "New York Times (1923-Current file)" on "Wall Street Journal” or "Wall Street Journal (Online)" on "The Washington Post (2008-Recent)") AND ((college-educated men) or (college-educated man)) AND ((Trump) or (election) OR (Clinton))) NOT non-college-educated

Number of articles in the 30 days post: 20

Number of articles in the 30 days prior: 30

Ratio:

\section{A3 Non-demographic Terms}

A3.1 Search Term: (populism) or (populist)

ProQuest search string: pub.Exact("The Washington Post (1974-Current file)" OR "New York Times (2008-Recent)" or "Wall Street Journal (1923-Current file)" on "New York Times (1923-Current file)" on "Wall Street Journal" or "Wall Street Journal (Online)" on "The Washington Post (2008-Recent)") AND ((populism) OR (populist)) AND ((Trump) OR (election) OR (Clinton))

Number of articles in the 30 days post: $\quad 595$

Number of articles in the 30 days prior: 259

Ratio: $\quad 2.30$

A3.2 Search Term: (globalization)

ProQuest search string: pub.Exact("The Washington Post (1974-Current file)" OR "New York Times (2008-Recent)" or "Wall Street Journal (1923-Current file)" OR "New York Times (1923-Current file)" on "Wall Street Journal" on "Wall Street Journal (Online)" OR "The Washington Post (2008-Recent)") AND (globalization) AND ((Trump) OR (election) OR (Clinton))

Number of articles in the 30 days post: $\quad 217$

Number of articles in the 3 o days prior: $\quad 82$

Ratio:

A3.3 Search Term: (white nationalism)

ProQuest search string: pub.Exact("The Washington Post (1974-Current file)" OR "New York Times (2008-Recent)" or "Wall Street Journal (1923-Current file)" on "New York Times (1923-Current file)" o "Wall Street Journal" o "Wall 
Street Journal (Online)" OR "The Washington Post (2008-Recent)") AND (white nationalism) AND ((Trump) OR (election) OR (Clinton))

Number of articles in the 30 days post: $\quad 85$

Number of articles in the 30 days prior: 40

Ratio:

A3.4 Search Term: (globalization victim) OR (globalization backlash)

ProQuest search string: pub.Exact("The Washington Post (1974-Current file)" OR "New York Times (2008-Recent)" OR "Wall Street Journal (1923-Current file)" OR "New York Times (1923-Current file)" OR "Wall Street Journal" o "Wall Street Journal (Online)" OR "The Washington Post (2008-Recent)") AND ((globalization victim) OR (globalization backlash)) AND ((Trump) OR (election) OR (Clinton))

Number of articles in the 30 days post: 19

Number of articles in the 30 days prior: 41

Ratio:

2.16 